\title{
QUANTUM EFFICIENCY OF THE LUMINESCENCE OF YTTERBIUM(III) $\beta$-DIKETONATES*
}

\author{
S.B. Meshkova, Z.M. Topilova, D.V. Bolshoy, S.V. Beltyukova
}

A.V. Bogatsky Physico-chemical Institute of National Academy of Sciences of Ukraine 86, Lustdorfskay a doroga, 270080, Odessa, Ukraine

M.P. TSVIRKo AND V.YA. VENCHIKoV

National Ozone Monitoring Research Center, Belorussian State University 7, Kurchatova St., 220064, Minsk, Belarus

(Received July 23, 1998; revised version February 25, 1999)

The processes of the energy deactivation of electronic excitation in $\mathrm{Yb}$ (III) $\beta$-diketonates and their dependence on the nature of $\beta$-diketone and the second ligand as well as the environment and its state (complexes in organic solvents and polymer matrix) were studied. Taking as an example the ytterbium thenoyltrifluoroacetonate, it was shown that the energy losses in the ligand and $\mathrm{Yb}(\mathrm{III})$ ion, which is due to the high-frequency vibrations of the central $\mathrm{C}-\mathrm{H}$ group of the $\beta$-diketone, can lead to the decreased quantum yield of the luminescence. The increase in the medium rigidity causes the decrease in losses in the ligand, but does not affect the deactivation of the $\mathrm{Yb}$ (III) ion excited level. In the mix-ligand complexes the second ligand (1,10-phenanthroline) improves the screening of the central ion providing almost full transfer of the energy, absorbed by ligand, to ytterbium ion.

PACS numbers: $78.55 . \mathrm{Cr}$

\section{Introduction}

The lanthanide $\beta$-diketonates are used not only for the separation of the elements of this series as converters of the light energy, luminescent markers of the biological molecules, etc., [1, 2], but also for the high sensitive detection of $\mathrm{Sm}$ (III) and $\mathrm{Eu}(\mathrm{III})$ [2], and recently, of $\mathrm{Nd}(\mathrm{III})$ and $\mathrm{Yb}(\mathrm{III})$ [2-4]. We have studied phy-

\footnotetext{
*The results of this paper were initially presented at The Jabtonski Centennial Conference
} on Luminescence and Photophysics, July 23-27, 1998, Torun, Poland. 
sicochemical and optical properties of these lanthanide compounds with the different derivatives of acetylacetone and found a correlation of some parameters of $\operatorname{Ln}$ (III) $\beta$-diketonates with the properties of ligands $[4,5]$. The energies of the excited triplet $T_{1}$ levels of $\beta$-diketones lie between 19600 and $23000 \mathrm{~cm}^{-1}$, corresponding to the gap between the $T_{1}$ level of the ligand and the excited level of Sm(III) and $\mathrm{Eu}$ (III) approximately $4000 \mathrm{~cm}^{-1}$, and for $\mathrm{Nd}$ (III), about $7500 \mathrm{~cm}^{-1}$. In contrast to the above lanthanide ions, ytterbium is characterized by one excited ${ }^{2} F_{5 / 2}$ and one ground ${ }^{2} F_{7 / 2}$ levels. The gap between the $T_{1}$ levels of ligands and the ${ }^{2} F_{5 / 2}$ level of $\mathrm{Yb}$ (III) considerably exceeds that for $\mathrm{Sm}$ (III) and $\mathrm{Eu}$ (III) and amounts to $10000-13000 \mathrm{~cm}^{-1}$. For this reason, on the one hand, the $\mathrm{Yb}$ (III) ion, to a greater degree than $\mathrm{Sm}$ (III), $\mathrm{Eu}(\mathrm{III})$, and $\mathrm{Nd}$ (III) ions, is subjected to quenching by the environment, mainly by water molecules, and on the other hand, it quenches itself the luminescence of lanthanide ions the excited levels of which are located higher.

Ytterbium $\beta$-diketonates are a good model system for the study of the processes of intra- and intermolecular energy deactivation. The availability of only one excited level of $\mathrm{Yb}$ (III) ion, the energy of which is (about $10000 \mathrm{~cm}^{-1}$ ) much lower than the energy of the lower triplet level of the anyone using $\beta$-diketones, allows to except from the examination the processes, with the participation of the lanthanide ion high-excited levels, was able to take part in the activation and deactivation processes of the luminescence. In addition, $\mathrm{Yb}$ (III) ion is characterized by a high probability of the radiative transition significantly more than that for $\mathrm{Eu}(\mathrm{III})$ ion which has the intensive luminescence in the complex with the fluorocontaining $\beta$-diketones.

For this reason, in this paper we studied the deactivation processes of the electronic energy excitation in the ytterbium $\beta$-diketonates and their dependence upon the nature of the main ( $\beta$-diketone, $\mathrm{L}$ ) and additional (1,10-phenanthroline, Phen) ligands, environment and its aggregate state.

\section{Experimental procedures}

Acetylacetone derivatives containing three or more carbon atoms in the fluorinated radical $\left(R_{F}\right)$ were synthesized using the procedure described elsewhere [5]. $\beta$-Diketones containing six or eight carbon atoms in $R_{\mathrm{F}}\left(-\mathrm{C}_{6} \mathrm{~F}_{13}\right.$ or $\left.-\mathrm{C}_{8} \mathrm{~F}_{17}\right)$ and also oxygen-containing $\beta$-diketones were synthesized for the first time. They were identified by the techniques of IR and NMR spectroscopy, gas-liquid chromatography, and elementary analysis. The purity of $\beta$-diketones was $98-99.5 \%$. The organic solvents were additionally purified by distillation according to [6].

The solid $\mathrm{Yb}(\mathrm{III})$ complexes were prepared as described elsewhere [2].

Deuteration of thenoyltrifluroacetone (TTA) in the central $\mathrm{C}-\mathrm{H}$ group was realized by replacing hydrogen in deuterated ethanol $\left(\mathrm{C}_{2} \mathrm{D}_{5} \mathrm{OD}\right)$ for $48 \mathrm{~h}$. Completeness of the deuteration was checked by ${ }^{13} \mathrm{C}$ NMR spectra.

The chelate solutions in non-polar solvents (toluene, four-chloride carbon) and polymer, poly(methyl methacrylate) (PMMA), were investigated. The polymeric samples were prepared as the films with thickness of $10 \mu \mathrm{m}$.

The absorption spectra of $\beta$-diketones and their $\mathrm{Yb}(\mathrm{III})$ complexes were recorded with a Specord $M-40$ spectrophotometer. The luminescence spectra were 
obtained on an SDL-2 spectrophotometer (Leningrad Opto-mechanical Association, St. Petersburg, Russia). Xenon lamp was used as an excitation source. The corrected spectra were obtained with a standard lamp. The luminescence lifetime was measured upon the laser excitation ( $\left.\lambda=355 \mathrm{~nm}, t_{\mathrm{mp}}=10 \mathrm{~ms}\right)$, its intensity was registered at the band maximum $(975 \mathrm{~nm})$. The resolution time of the registration system is $100 \mathrm{~ns}$.

Since the reference substance that absorbs in a field of $340 \mathrm{~nm}$ and emits in a field of $975 \mathrm{~nm}$ is absent, the luminescence quantum yield of $\mathrm{Yb}$ (III) $\beta$-diketonates was measured by the absolute method on the homemade plant [7].

\section{Results and discussion}

As an example the luminescence spectra of double and mix-ligand, including 1,10-phenanthroline, $\mathrm{Yb}$ (III) complexes with acetylacetone thienyl derivatives are presented in Fig. 1. The obtained molar extinction coefficients $(\varepsilon)$, quantum yield and lifetime of luminescence for the $\mathrm{Yb}(\mathrm{III})$ complexes with the mentioned $\beta$-diketones are given in Tables I and II.

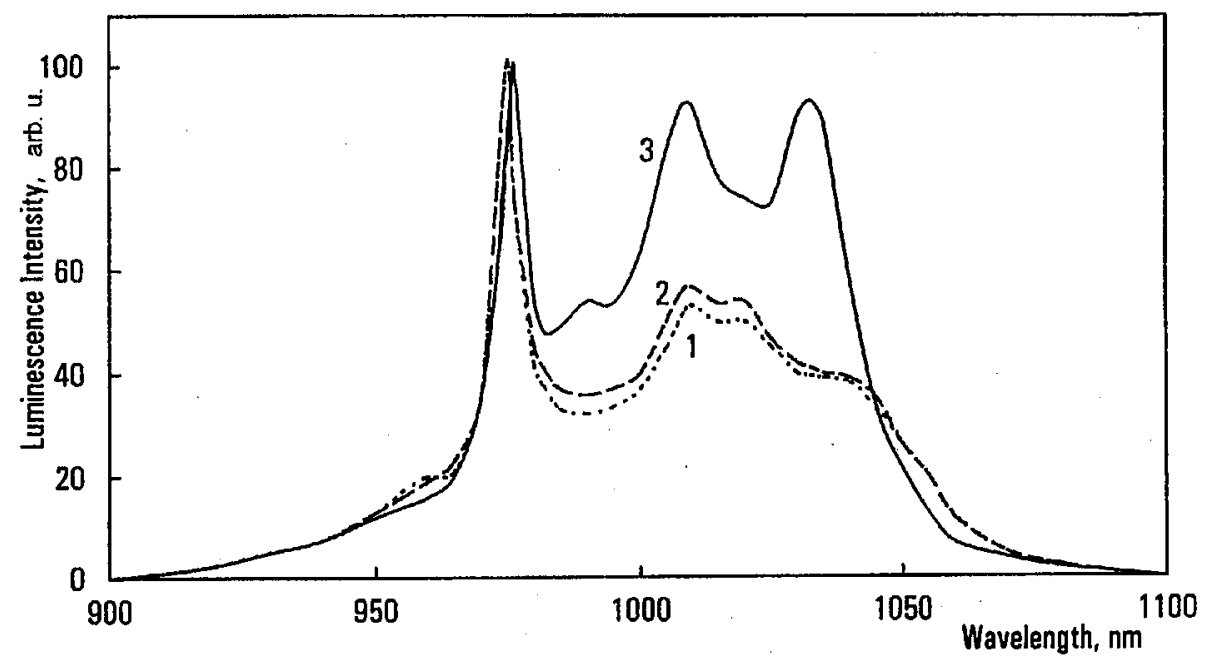

Fig. 1. The luminescence spectra of double $(1,2)$ and mix-ligand (including 1,10phenanthroline) (3) $\mathrm{Yb}$ (III) complexes with acetylacetone thienyl derivatives containing $R_{\mathrm{F}}=\mathrm{CF}_{3}(1,3)$ and $R_{\mathrm{F}}=\mathrm{C}_{6} \mathrm{~F}_{13}(2)$. Solutions in toluene.

The analysis of the obtained data allows to estimate the role of the main and additional ligands in the processes of deactivation of electronic excitation energy, the role of the medium and the influence of its rigidity.

A comparison of calculated values of molar extinction coefficients shows that: in the case of double complexes $\left(\mathrm{YbL}_{3}\right)$ the lengthening of $R_{\mathrm{F}}$ leads to the increase in their absorbance. However, neither the length of $R_{\mathrm{F}}$ nor medium rigidity affect significantly the absorbance of the mix-ligand complexes ( $\left.\mathrm{YbL}_{3} \mathrm{Phen}\right)$.

As one can see from the luminescence spectra of the double complexes ( $\mathrm{YbL}_{3}$ ), the lengthening of $R_{\mathrm{F}}$ chain $\mathrm{CF}_{3}$ to $\mathrm{C}_{6} \mathrm{~F}_{13}$ leads to insignificant relative increase in the long wave wing and does not affect the position of the main 
TABLE I

Spectral-luminescence characteristics of double and mix-ligand, including 1,10-phenanthroline, Yb(III) complexes with thienyl derivatives of acetylacetone* in solutions and polymeric matrix.

\begin{tabular}{c|c|r|r|r|r|r|r|r|r|r|r}
\hline \hline \multicolumn{2}{c|}{ Ligands } & \multicolumn{3}{c|}{$\varepsilon \times 10^{-4}$} & \multicolumn{2}{c|}{$\varphi \times 10^{3}$} & \multicolumn{3}{c|}{$\tau[\mu \mathrm{s}]$} & \multicolumn{2}{c}{$\varphi / \tau \times 10^{-3} \cdot\left[\mathrm{s}^{-1}\right]$} \\
\hline $\begin{array}{c}\beta \text {-diketone } \\
\left(R_{\mathrm{F}}\right)\end{array}$ & $\begin{array}{c}\text { second } \\
\text { (additional) }\end{array}$ & toluene & $\mathrm{CCl}_{4}$ & PMMA & toluene & PMMA & toluene & $\mathrm{CCl}_{4}$ & PMMA & toluene & PMMA \\
\hline $\mathrm{CF}_{3}$ & - & 4.2 & 3.8 & 4.3 & 3.5 & 5.5 & 5.7 & 4.3 & 9.7 & 0.61 & 0.57 \\
$\mathrm{CF}_{3}$ & Phen & 4.8 & 4.4 & 4.3 & 11.0 & 11.1 & 10.4 & 11.9 & 10.7 & 1.06 & 1.03 \\
$\mathrm{C}_{3} \mathrm{~F}_{7}$ & - & 4.4 & 4.3 & 4.1 & 2.6 & 3.7 & 8.6 & 5.4 & 11.0 & 0.30 & 0.34 \\
$\mathrm{C}_{3} \mathrm{~F}_{7}$ & Phen & 6.1 & 5.5 & 4.6 & 12.0 & 12.0 & 11.7 & 11.9 & 11.1 & 1.02 & 1.12 \\
$\mathrm{C}_{6} \mathrm{~F}_{13}$ & - & 4.3 & 4.3 & 4.0 & 2.4 & 4.2 & 9.2 & 5.6 & 11.4 & 0.26 & 0.37 \\
$\mathrm{C}_{6} \mathrm{~F}_{13}$ & Phen & 4.7 & 4.3 & 4.4 & 8.8 & 10.0 & 11.8 & 11.3 & 11.0 & 0.75 & 0.91 \\
\hline
\end{tabular}

${ }^{*} R_{\mathrm{F}}-\mathrm{CO}-\mathrm{CH}_{2}-\mathrm{CO}-\left(\prod_{\mathrm{S}}\right)$ 
TABLE II

Spectral-luminescence characteristics of double and mix-ligand $\mathrm{Yb}(\mathrm{III})$ complexes with phenyl derivatives of acetylacetone*; solutions in toluene.

\begin{tabular}{c|c|c|c|r|c}
\hline \hline \multicolumn{2}{|c|}{ Ligands } & $\varepsilon \times 10^{-4}$ & $\varphi \times 10^{3}$ & $\begin{array}{c}\tau \\
{[\mu \mathrm{s}]}\end{array}$ & $\begin{array}{c}\varphi / \tau \times 10^{-3} \\
{\left[\mathrm{~s}^{-1}\right]}\end{array}$ \\
\cline { 1 - 4 } $\begin{array}{c}\beta \text {-diketone } \\
\left(R_{\mathrm{F}}\right)\end{array}$ & $\begin{array}{c}\text { second } \\
\text { (additional) }\end{array}$ & & & & \\
\hline $\mathrm{CF}_{3}$ & - & 3.4 & 1.1 & 1.8 & 0.61 \\
$\mathrm{CF}_{3}$ & Phen & 3.8 & 6.5 & 10.4 & 0.63 \\
$\mathrm{C}_{3} \mathrm{~F}_{7}$ & - & 4.0 & 1.5 & 2.5 & 0.60 \\
$\mathrm{C}_{3} \mathrm{~F}_{7}$ & Phen & 4.2 & 8.8 & 10.7 & 0.82 \\
$\mathrm{C}_{6} \mathrm{~F}_{13}$ & - & 4.4 & 1.7 & 2.6 & 0.65 \\
$\mathrm{C}_{6} \mathrm{~F}_{13}$ & Phen & 4.6 & 9.8 & 11.0 & 0.89 \\
$\mathrm{C}_{8} \mathrm{~F}_{17}$ & - & 4.8 & 1.9 & 2.5 & 0.76 \\
$\mathrm{C}_{8} \mathrm{~F}_{17}$ & Phen & 4.1 & 9.2 & 10.5 & 0.88 \\
\hline
\end{tabular}

${ }^{*} R_{\mathrm{F}}-\mathrm{CO}-\mathrm{CH}_{2}-\mathrm{CO}-\bigcirc$

luminescence band (Fig. 1, spectra 1 and 2). This confirms the weak influence of $R_{F}$ length on the electronic shell of $\mathrm{Yb}(\mathrm{III})$ ion and, in accordance with the data of the absorption spectra, is due to the inhomogeneous widening at the lengthening of $R_{\mathrm{F}}$.

The addition of the second ligand (Phen), causing the long wave shift of the main maximum $(980 \mathrm{~nm})$ and the significant increase in the intensity of the long wave wing with the appearance of the pronounced maxima at 1008 and $1033 \mathrm{~nm}$ (Fig. 1, spectrum 3), affects much more the luminescence spectrum of $\mathrm{Yb}(\mathrm{III})$ ion. In the luminescence spectra of $\mathrm{YbL}_{3}$ Phen, as well as in the absorption spectra, no significant influence of the chain length and medium rigidity is observed. All this points out that the addition of the second ligand (Phen) not only screens the $\mathrm{Yb}(\mathrm{III})$ ion from the influence of the outer medium, but can transform its outer structure in a larger degree than the lengthening of $R_{\mathrm{F}}$ chain of $\beta$-diketone.

The data on the quantum yield of luminescence $(\varphi)$ confirm the mentioned above hypothesis. Thus, the addition of the second ligand (Phen) leads to the considerable increase in $\varphi$, the values of which become close to each other and weakly depend on the nature of $\beta$-diketone (Table I, II). At the same time for the double complexes the significant dependence of $\varphi$ on the ligand nature is observed and it is impossible to explain this only by different screening the lanthanide ion by the ligand from influence of environment, since the values of luminescence lifetime $(\tau)$ for all the complexes are close (Table I, II) and, consequently, the probabilities of deactivation of the excited state of $\mathrm{Yb}(\mathrm{III})$ are also close. Reducing the ratio of quantum yield to the luminescence lifetime $(\varphi / \tau)$ in double $\mathrm{Yb}(\mathrm{III})$ complexes indicates the energy losses of electronic excitation in the ligand as a result, it does not completely reach the central ion. In the mix-ligand complexes including also Phen, 
apparently, the total energy of the electronic excitation, absorbed by the ligand, is transferred to the $\mathrm{Yb}(\mathrm{III})$ ion. Such a conclusion can be made from a comparison of the $\varphi / \tau$ values with the probability of corresponding emissive transition of the $\mathrm{Yb}$ (III) ion which according to [8] is $1500 \mathrm{~s}^{-1}$. The ratio of luminescence quantum yield to luminescence lifetime of $\mathrm{Yb}$ (III) ion gives the product of probability of emissive transition by quantum yield of the energy transfer from the ligand to $\mathrm{Yb}(\mathrm{III})$ ion. Assuming that probability of emissive transition for $\mathrm{Yb}(\mathrm{III})$ ion, as for other $\operatorname{Ln}(\mathrm{III})$ ions, the open $4 f$-shell of which is screened by the outer $5 d$-electrons, does not depend very much on the type of compound containing this ion, then it can be expected that in $\beta$-diketone complexes the probability of $\mathrm{Yb}(\mathrm{III})$ emissive transition will be about $10^{-3} \mathrm{~s}$.

As can be seen from Table I and II, the $\varphi / \tau$ values for mix-ligand complexes $\left(\mathrm{YbL}_{3} \mathrm{Phen}\right)$ are close to each other and are about $10^{-3} \mathrm{~s}$, i.e. actually all the energy, absorbed by the ligand, is transferred to the central ion. At the same time for the double complexes $\left(\mathrm{YbL}_{3}\right)$ the $\varphi / \tau$ ratio is by $2-3$ times less than in the mix-ligand ones, that may be also connected with the reducing of the probability of emissive ${ }^{2} F_{5 / 2} \rightarrow{ }^{2} F_{7 / 2}$ transition. However, since $\tau$ values for the double and mix-ligand in PMMA are actually the same, the lower $\varphi / \tau$ values, apparently, are connected with increasing the probability of non-radiative deactivation of the energy in the ligand and its competition with intramolecular energy transfer from the ligand to $\mathrm{Yb}(\mathrm{III})$ ion.

Among the investigated $\mathrm{Yb}$ (III) $\beta$-diketonates the influence of aggregate state of the medium on luminescence quantum yield is pronounced in a greatest degree for $\mathrm{Yb}(\mathrm{DBM})_{3}$ Phen, for which the quantum yield is reduced by 7 times when traveling from the polymeric matrix $\left(\varphi=0.91 \times 10^{-3}\right)$ to the solution in toluene $\left(\varphi=0.13 \times 10^{-3}\right)$. In this case the luminescence lifetime of $\mathrm{Yb}$ (III) ion changes very weakly ( $\tau=8$ and $9 \mu$ s in PMMA and toluene respectively) indicating the rise of additional losses rather in a ligand than in $\mathrm{Ln}$ (III) ion and can be explained by the formation of the conformers in non-rigid media, arising from the excited states of the ligand, for instance, as a result of the rotation of phenyl rings around a single bond. For the thienyl derivatives the influence of medium rigidity on luminescence quantum yield is considerably weaker and in the case of mix-ligand complexes it is actually absent (see Table I).

The absence of the dependence of luminescence lifetime and, consequently, all the processes of the excited state deactivation of $\mathrm{Yb}(\mathrm{III})$ ion on aggregate state of the medium in all the investigated mix-ligand complexes (see Table I) should be especially noted. A slight decrease in luminescence lifetime of the double $\mathrm{Yb}$ (III) $\beta$-diketonates when traveling from the polymeric matrix to the solution can be connected with the presence of water traces in the organic solvent that is included into the first coordination sphere of $\mathrm{Yb}$ (III) ion to increase the probability of its non-radiative deactivation.

Analysis of the data obtained demonstrates that rigidity of the medium in fact does not affect the deactivation processes of the excited state of $\mathrm{Yb}$ (III) ion but can significantly influence the non-radiative deactivation processes in the ligand competing with intramolecular energy transfer from the ligand to the ytterbium ion. However, when the second ligand (Phen) is incorporated the influence of the 
medium rigidity is relaxed and in this case it can be explained by the increased rigidity of the complex.

The presence of losses in ligand reduces the luminescence quantum yield of $\mathrm{Yb}$ (III) $\beta$-diketonates, however, the main reason for its low value is the quenching of $\mathrm{Yb}$ (III) excited level. As it can be seen from Tables I and II, luminescence lifetime of $\mathrm{Yb}(\mathrm{III})$ in all the investigated complexes is actually the same and about $10^{-5} \mathrm{~s}$ that is significantly less than the lifetime of its emissive transition $\left(10^{-3} \mathrm{~s}\right)$. The general reason for quenching the excited states of $\operatorname{Ln}(\mathrm{III})$ ions is the energy transfer to the corresponding overtones of high-frequency vibrations of nearest environment [8]. Here, the high-frequency vibrations of both ligand and solvent can participate in the deactivation of the excited states of $\operatorname{Ln}(\mathrm{III})$ ion. As it can be seen from Table I, the traveling from toluene to $\mathrm{CCl}_{4}$, containing no high-frequency vibrations, does not lead to the increase in luminescence lifetime which confirms the dominating role of the ligand. The close $\tau$ values for the double and mix-ligand complexes, including also Phen, point out the slight participation of second ligand in the process of deactivation of $\mathrm{Yb}$ (III) excited level. In addition, the $\tau$ values do not depend on the $\beta$-diketone nature.

The combination of all the obtained data may be explained with the assumption that overtones of high-frequency vibration of the central $\mathrm{C}-\mathrm{H}$ group, present in all $\beta$-diketones, perform the main role in deactivation of $\mathrm{Yb}$ (III) excited level, here the role of side substituents $\left(R_{1}\right.$ and $\left.R_{2}\right)$ is insignificant.

The dominating role of the central $\mathrm{C}-\mathrm{H}$ group, apparently, is explained by the fact that it is a single hydrogen-containing one in six-member chelate cycle, formed by $\mathrm{Yb}(\mathrm{III})$ ion and $\beta$-diketone.

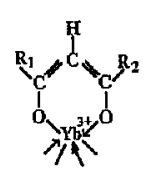

Deactivation of $\mathrm{Yb}(\mathrm{III})$ ion excited state by high-frequency vibrations of $\beta$-diketone $\mathrm{C}-\mathrm{H}$ groups was studied taking as an example the thenoyltrifluoroacetonate complexes. Replacing $\mathrm{H}_{2} \mathrm{O}$ by $\mathrm{D}_{2} \mathrm{O}$ in the double complex leads to the increase by 1.46 times of luminescence quantum yield of $\mathrm{Yb}(\mathrm{III})$ ion and the deuteration of $\beta$-diketone gives the additional increase in $\varphi$ by 1.15 times. In the case of mix-ligand complexes the relative increase in $\varphi$ was 1.46 and 1.05 respectively.

As follows from the above, the share of non-radiative losses, expanding in high-frequency vibrations of $\mathrm{OH}$ oscillators, is considerably higher than in the vibrations of ligand $\mathrm{C}-\mathrm{H}$ groups.

Thus, the performed investigation has demonstrated that the losses of energy both in the ligand itself and in $\mathrm{Yb}$ (III) ion, that are determined by high-frequency vibrations of the central $\mathrm{C}-\mathrm{H}$ groups in $\beta$-diketone, can lead to the increase in luminescence quantum yield of $\mathrm{Yb}(\mathrm{III})$ ion in the complexes with $\beta$-diketones. The increase in medium rigidity causes reducing the losses in ligand but does not affect the deactivation of the excited state of $\mathrm{Yb}(\mathrm{III})$ ion. The formation of mix-ligand complex upon introduction of neutral ligand (Phen) into the $\mathrm{Yb}$ (III) $\beta$-diketonate molecule improves screening of the central ion providing actually complete transfer of energy, absorbed by the ligand, to the ytterbium ion. 


\section{References}

[1] S.P. Sinha, Complexes of the Rare Earths, Pergamon Press, London 1966.

[2] N.S. Poluektov, L.I. Kononenko, N.P. Efryushina, S.V. Bel'tyukova, Spectrofotometricheskie i lyuminestzentnye metody opredeleniya lantanoidov (Spectrophotometric and Luminescence Methods for Assay of Lanthanides), Naukova Dumka, Kiev 1989.

[3] M. Morin, R. Bador, H. Dehaud, Anal. Chim. Acta 219, 67 (1989).

[4] Z.M. Topilova, N.V. Rusakova, S.B. Meshkova, M.O. Lozinsky, L.S. Kudryavtceva, L.I. Kononenko, Zh. Anal. Khim. 46, 863 (1991).

[5] N.V. Rusakova, Z.M. Topilova, S.B. Meshkova, M.O. Lozinsky, Yu.I. Gevaza, $Z h$. Neorg. Khim. 37, 116 (1992).

[6] A. Wiserberger, E. Proskauer, D. Ryddick, E. Tupes, Organic Solvents. Physical Properties and Purification Methods. Translated under the title Organicheskie rastvoriteli. Fizicheskie svoistva $i$ metody ochistki, Inostrannaya Literatura, Moscow 1958.

[7] V.Ya. Venchikov, V.E. Pyatosin, M.P. Tsvirko, Zh. Prikl. Spektrosk. 58, 204 (1993).

[8] E.B. Sveshnikova, V.L. Ermolaev, Opt. Spektrosk. 30, 379 (1974). 